\title{
SMART CITIES WITH ENERGY MANAGEMENT EFFICIENCY: A CONCEPT OF ANCIENT TIME
}

\author{
Somya Tiwari ${ }^{1}$, Pratibha Kumari Singh ${ }^{2}$ \\ E-Mail ID: ${ }^{1}$ somyatiwari@ansaluniversity.edu.in, ${ }^{2}$ pratibha.vishen@gmail.com \\ ${ }^{1}$ School of Engineering and Technology, Ansal University, Gurgaon, Haryana, India \\ ${ }^{2}$ Jettwings Institute, Gangtok, Sikkim, India
}

\begin{abstract}
Present paper explores the concept of smart cities, its features, attributes and ways in which it can manage the energy efficiently for sustainability. Brining case study of ancient cities of Harappa and Mohenjo-Daro, the author suggest that their study could bring ways in which these cities managed resources and maintained sustainability in those time. The paper, thus presents energy efficiency strategies and probable solutions for sustainability that could pave the way for the evolutionary concept of the smart cities.
\end{abstract}

Keywords: Renewable energy, sustainability, Heritage cities, Smart cities.

\section{INTRODUCTION}

Indian heritage is a marvel from the perspectives of planning, architecture and energy efficiency of resources for the presence of these monuments till date is a testimony of their robustness and sustainability. These architectures seed the future of smart cities and thus we can say, the heritage cities can provide blue print for what a smart city should stand for. Established on the river banks, these cities provide a successful model for energy efficiency and sustainability. These cities had well planned palaces, residential buildings, towns and villages, dams, water supply system, shopping centers, public spaces and sophisticated drainage systems that ensured their survival and sustainability against the wrath of rainfalls, man-made and natural calamities and disasters.

Mohenjo-Daro and Harappa reveal the sophisticated engineering by the craftsmen that allowed country men to live peacefully and holistically in the quarters and colonies. The history and excavations revealed the effective methods that were used to sustain infrastructures for longer. The history of these cities authenticates, without the sources of renewable energy, it would have been impossible for them to survive for such long. In light of history of these cities, we can understand the still evolutionary concept of smart cities (Raja, 2016).

\section{SMART CITIES}

The growth in the world's urban population will increase by $75 \%$ as predicted by the United Nations, thus, propelling the mass migration to the cities that would need urban authorities to prepare smart cities that could cater to such demands. This unprecedented population and urbanization rise demands construction of smart cities that ensure quality life to its residents keeping the demographic, social, economic and environmental challenges.

The concept of smart cities covers a wide spectrum that include focus on quality of life, communication technology, disaster and waste management, availability of clean drinking water, parks and gyms, health care, public transport, education and public safety. These cities use all the available and advanced technologies in an intelligent, optimal manner that ensures energy efficiency and sustainability for the establishment of urban housing that are integrated, holistic, habitable, brining health, social cohesion and prosperity to the residents (Ejaz et. \& 2017, Silva, Khan, \& Han, 2018).

Through this paper, we want to establish that the concept of smart cities is not new, thought evolving in nature, for the cities, since beginning have been constructed, built and planned as per the needs, requirements of the citizens, with the most advanced technologies and architectural designs available at that point in time. With the technological advancement and internet of the things and digitization, we are adding new features that add energy optimization, a mandatory feature to be added for sustainability.

Sustainability and energy management are the two key areas that the authors want to cover and highlight in this paper. The presence of India's Heritage cities and rich monuments is a testimony of the brilliant architecture that withstood the tests and tides of time for such long. The natural calamities and disasters have brought changes, however, their robust architect have saved and kept them intact for so long. Further, besides the sustainability, that has the elements of design, layout, use of construction material, selection of construction sites, that is significant, we also understand, without energy, survival is endangered. Therefore, energy management of the resources becomes an important concept for us. These heritage cities thus can provide significant insights and revelations for the smart cities on the questions of planning, building, use of material, design, layout, energy efficiency, to name a few.

\section{ENERGY MANAGEMENT}

Energy requirements for the smart cities are complex and abundant. Optimal solutions and strategies are thus required to implement them in coordinated way. Simulation methods are used by the stakeholders to understand the overall energy consumption in these cities and thus, to devise probable synergies for their effective usage. Although, to get a 
complete and realistic picture of that demand and supply becomes a far-fetched thing, and thus, a comprehensive smart-city model is desirable to get the energy needs. An analysis of heritage cities gives us this exposure that management of renewable energy resources has been excellent with them (Calvillo, Sánchez-Miralles, \& Villar, 2016). To minimize the loss of energy or maximize the utilization of energy ancient history has many examples of energy management. One of the best effort done was cities are near to river and planned in such a manner that distance required to reach daily essentials is minimum which is time saving too. One of the most talked thing in smart city is zero energy requirement.

\subsection{Minutes City Tour}

Keeping in mind to avoid drastic traffic which lead to energy consumption as well as pollution addition in the environment why not planned cities in such way that essentials things are available to mankind in walking distance which is given name the project 15 Minutes city tour. To recover the Covid-19 recovery plan. Few of the European cities are already made in that concept in which Paris is one of the example.

In this concept air pollution will highly get impacted as most of the daily need can be accessible by citizen on walking or using cycle ride. There will be no dependency on vehicles. Life quality will get improved as this will be going to cutting down commuting duration. It is started with C40 cities with the coalition of 96 elected city representatives.

\subsection{Renewable Energy Utilization}

Urban living is design in such a manner that high rise buildings are in demand which makes the system to consumption more energy. In the present era of globalization energy demand is increasing but latest development and adaptation towards these changes are coming in the field of renewable energy. In ancient times living were design to utilized maximum of solar energy. So as per the weather also different places were made to make living comfortable by utilizing natural energy available. Nowadays demand of renewable energy is rapidly growing as it will be future energy solution for sure. Wind energy is producing world's most of the energy where it is available. Solar is another market of clean and green energy supply. Solar photovoltaic is providing solution to electricity demand as this is energy of sun which is available throughout the year (Jäger-Waldau, 2020). Latest research is also going on efficient energy storage and distribution. Modern smart cities should be smart enough to produce or convert day to day energy need by clean and green energy. Only technology enhancement is not the solution as each and energy modern appliance or service need uninterrupted energy supply and contribution towards pollution.

\section{SUSTAINABILITY}

Sustainability is based on the pillars of human, economic, environmental and social development that ensures that resources-renewable and non- renewable remain for future generations while we live a quality life, using resources efficiently and optimally. Enriched with renewable sources of energy in all its forms, sustainability encapsulates dependence and interdependence on these renewable sources that allow us to live in unison. These energies are axiomatic for our survival. The energy sustainability 3E's are energy security, energy equity and environmental sustainability (Villa-Arrieta, M., \& Sumper, A., 2019).

Heritage buildings present their environment friendliness, dependence on natural system and a variety of sustainable practices. It is possible to revive some of these practices and implement them into Smart cities. The study of heritage buildings provides an insight on how the sustainable practices of reduced consumption, recycling and reuse were encouraged through water management and harvesting, providing designs of natural ventilation for air and sunlight, climate adaptive patters to save energy to name a few that were made part of the buildings. (Raja, 2016 \& Silva et 2018).

Location of these cities on the river banks, highlight, how the kings and emperor were selective in selection of construction sites. The town planning at Mohenjo-Daro, Harappa, Lothal and Nalanda showcase marvelous architectural precision that ensures sustainability and energy management. The water storage and sewer system exhibit proper water management at these places, the buildings and roads were such planned and constructed that they would receive proper sunlight and wind to remain lit and comfortable throughout the day. Greenland, woods, forests, parks and gardens had been an integral part of all these ancient monuments and buildings. These green areas ensured balance in the temperature besides the aesthetic aspect of the buildings. Hawa Mehal from Jaipur is a testimony that showcases architectural brilliance wherein natural sunlight and breeze comes in the rooms of the Mahel giving it a natural ambience and ensuring its sustainability.

Since the concept of smart cities involves interconnect of trans disciplinary areas, it becomes pertinent to bring expertise from all these fields and integrate them in holistic way. Internet of the things and ICT make these cities smart, however, some of the practices from the heritage cities mentioned in the above paragraphs could be replicated and integrated into the smart cities to make them smarter and the most efficient.

\section{METHODS}

In the stipulated time frame, the authors have taken the sample of the ancient cities from India that allowed them to create a matrix of the renewable sources of energy. From the various components that feature smart cities, the authors focused on energy management and sustainability so as to limit the scope of the paper. 


\section{DISCUSSIONS}

Through discussions, the authors want to compare and contrast the renewable sources of energy, in the ancient time and the modern time and want to focus on the way forward for the sustainable future. Authors want to highlight that the ancient texts such as Vastushasta has all the details that delineates requirements of the smart cities. When stakeholders and architects would be well versed in these ancient texts and would have studied the pattern and design of the heritage cities, that would empower them with the insight to design and plan the smart cities that could meet the energy demands and sustain the hard and soft times like these monuments and heritage cities.

\section{SCOPE FOR FURTHER STUDY}

An exhaustive study could be conducted keeping all the renewable sources and keeping the demographic profile of the cities. There are many other Vedic and puranic texts that could be explored by the researchers to study bring new revelations. Scientific study of heritage cities with specific component corresponding to requirement in demand could be studied by the academicians and researchers.

\section{CONCLUSION}

The paper focused on the concept of smart cities, their features and issues of sustainability and energy efficiency management. While a buzzword that the smart cities have become, authors underpinned its relevance in the present times looking at the urbanization and sustainability perspectives and unpuzzled some of the dimensions by bringing fundamentals and basics from the ancient scriptures and heritage cities. Insights from heritage cities highlighted how the details of each of these aspects of energy management and sustainability had been practiced in them and their thorough study deepens understanding and sharpens holistic principles to be followed that shall maintain quality ecosystem, integrated and cohesive life in these cities with a vision and promising opportunities for the future.

\section{REFERENCES}

[1] Barrionuevo, J. M., Berrone, P., \& Costa, J. E. (2012). Smart Cities, Sustainable Progress: Opportunities for Urban Development. IESE Insight, (14), 50-57. doi:10.15581/002.art-2152

[2] Calvillo, C., Sánchez-Miralles, A., \& Villar, J. (2016). Energy management and planning in smart cities. Renewable and Sustainable Energy Reviews, 55, 273-287. doi:10.1016/j.rser.2015.10.133

[3] Ejaz, W., Naeem, M., Shahid, A., Anpalagan, A., \& Jo, M. (2017). Efficient Energy Management for the Internet of Things in Smart Cities. IEEE Communications Magazine, 55(1), 84-91. doi:10.1109/mcom.2017.1600218cm

[4] Pellicer, S., Santa, G., Bleda, A. L., Maestre, R., Jara, A. J., \& Skarmeta, A. G. (2013). A Global Perspective of Smart Cities: A Survey. 2013 Seventh International Conference on Innovative Mobile and Internet Services in Ubiquitous Computing. doi:10.1109/imis.2013.79

[5] Raja, S. (2016). Glimpses of Ancient Indian Town Planning for Building Modern Heritage Cities. Dev Sanskriti Interdisciplinary International Journal, 7, 07-11. doi:10.36018/dsiij.v7i0.71

[6] Silva, B. N., Khan, M., \& Han, K. (2018). Towards sustainable smart cities: A review of trends, architectures, components, and open challenges in smart cities. Sustainable Cities and Society, 38, 697-713. doi:10.1016/j.scs.2018.01.053

[7] https://www.c40.org/researches/arup-c40-baseline-report (Accessed on 25 June 2020)

[8] Wind energy: current status and prospects in Indian Context" International Journal of Advance Research in Science \&amp; Engineering, Volume 04, Issue 11, November 2015 ISSN -2319- 8354.Impact Factor 1. 142, page 173-178.

[9] Renewable Energy Potential and Sustainable Development in present scenario of Globalization" in the Journal of C.V.R. College Hyderabad, Issue 1, July 2011.

[10] Jäger-Waldau, A. (2020). Snapshot of Photovoltaics-February 2020. Energies, 13(4), 930.

[11] Villa-Arrieta, M., \& Sumper, A. (2019). Contribution of smart cities to the energy sustainability of the binomial between city and country. Applied Sciences, 9(16), 3247. 